\title{
Dimorphic Morphological Features between Sexes of Semiplotus semiplotus McClelland
}

\author{
K. Bagra ${ }^{1 *}$, B.A. Laskar ${ }^{2}$ and D.N. Das ${ }^{2}$ \\ ${ }^{1}$ Centre of Biodiversity, Rajiv Gandhi University, Itanagar- 791112, Arunachal Pradesh, India \\ ${ }^{2}$ Department of Zoology, Rajiv Gandhi University, Itanagar- 791112, Arunachal Pradesh, India \\ *E-mail:bagrakb@gmail.com
}

Received: 22.10.2009, Accepted: 17.12.2009

\begin{abstract}
Understanding of secondary sexual dimorphism in fish is an uphill task and the phenomenon is paradoxical in different species. Considering the importance, a study was carried out to identify the distinguishing morphological characters between the sexes of Semiplotus semiplotus(McClelland). It is a hill-stream fish species endemic to Eastern Himalayas and also important as food. Statistical analys is of various morphological measurements and meristic counts of 30 numbers of freshly collected specimens was the tool of the study. Together, some morphological peculiarities have also been noted for the seasonal sexual dimorphism. The females were found having longer anal fin height than the males by an average of $3.96 \mathrm{~mm}$. Again, the formation of keratinized tubercles on the anal fin of males versus smooth anal fin in females was also observed during breeding season. However, meristic counts were similar in both the sexes.
\end{abstract}

Key words: Sexual dimorphism, anal fin, tuberc les

\section{Introduction}

Semiplotus semiplotus (McClelland) (Figure $1-2)$ belonging to the family cyprinidae is one of the important freshwater food fishes in North Eastern part of India with its restricted distribution in the rivers of Eastern Himalayas (Vishwanath and Kosygin, 2000). In general the information on the variation of morphological characters and the external features is important for taxonomic identification as well as sexual dimorphism of fish (Jyoti and Sharma, 2006). Many have reported that morphological sexual dimorphism in fish ranges from changes in body colouration, rapid growth in the first and second spines of the dorsal fin (Park et al., 2001), formation of tubercles on the fins during breeding season (Jyoti and Sharma, 2006), etc. Conway and Britz (2007) have described extreme osteological sexual dimorphism of the axial skeleton, in particular elements of Weberian apparatus and the fifth vertebra of Sundadanio axelrodi (Brittan). Survey of literature revealed no such information on $S$. semiplotus, hence the present study was sought to analyse the variations in various morphometric and meristic characters towards sexual dimorphism of the species.

\section{Materials and methods}

The specimens of $S$. semiplotus were freshly collected from River Sipu at Doji village of the district West Siang of the state Arunachal Pradesh, India during October, 2006 to December, 2008. A total of 30 
numbers of specimens in the size range of $132 \mathrm{~mm}$ to $278 \mathrm{~mm}$ were subjected for morphometric measurements and meristics counts following Kottelat (2001). All the measurements were taken from point to point using vernier and digital calipers to the nearest of $0.10 \mathrm{~mm}$. The characters in head region viz. head height at occiput, head width at operculum, snout length, eye diameter, inter orbital distance and mouth gap were expressed in terms of percentile of head length. The other measurements were expressed in terms of percentage of standard length. All the data were pooled together, compared and the sex was identified through dissection. The variations in the parameters between the sexes were analysed statistically using SPSS 10.0 and MS Excel to establish the most distinguishing dimorphic characters.

\section{Results and discussion}

All the studied morphometric parameters for both male and female are presented in Table 1 and Figure 3, which depict that most of the parameters virtually differ between the sexes, but the variations are not statistically significant. No variation in the merismetic counts between both the sexes was observed.

Following the t-test of variation in those parameters which have been found statistically significant are considered sexually dimorphic. That the $\%$ of anal fin height on standard length of female (Figure 4A) was found longer than that of male (Figure 4B) by an average of $3.96 \mathrm{~mm}$; where the mean for male and female was recorded as $22.97 \pm 0.90$ and $26.93 \pm 1.31$ $\mathrm{mm}$ respectively. The calculated values of the $t$-test of the difference in percentage of anal fin height on standard length between both the sexes is 7.66; which is significant at $5 \%$ label of probability with degree of freedom 14.

The study unearthed a most conspicuous character that the males were observed to have developed series of tubercles on the anal fin (Figure 5A) during the breeding season which starts from the month of June and lasts up to October. Such character was not observed in case of female (Figure 5B).

Nikolsky (1963) stated that males and females often differ in the length and shape of the fins. According to him, in the males of many Cyprinoids, both the paired and the unpaired fins are slightly larger than the females. He cited examples of some species where male were found to differ in length and shape of fins. For example, in the males of certain lake Baikal Sculpins, the thoracic fins were found to be significantly larger. $\mathrm{He}$ further stated that in Xiphophorus (Family Pocciilidae) there is a long outgrowth on the caudal fin whereas in the males of many pleuronectids of the family Bothidae, the rays of the dorsal fin are elongated, and so on. Appearance of tubercles in different areas of the body during breeding season has been observed in 17 families of bony fishes under 5 orders; namely Salmoniformes, Gonorhynchiformes, Cypriniformes, Scorpaeniformes and Perciformes (Jyoti and Sharma, 2006). These breeding tubercles are local keratinizations distinctly different from normal epidermis and they facilitate contact between the individual fishes during breeding (Jyoti and Sharma, 2006).

Hence, the mentioned differences in the morphometric characters noted for males and females of the species S. semiplotus may be considered as sexually dimorphic feature.

Understanding of secondary sexual dimorphism in fish is an uphill task and the 
K. Bagra, B.A. Laskar and D.N. Das / Our Nature (2009) 7: 158-162

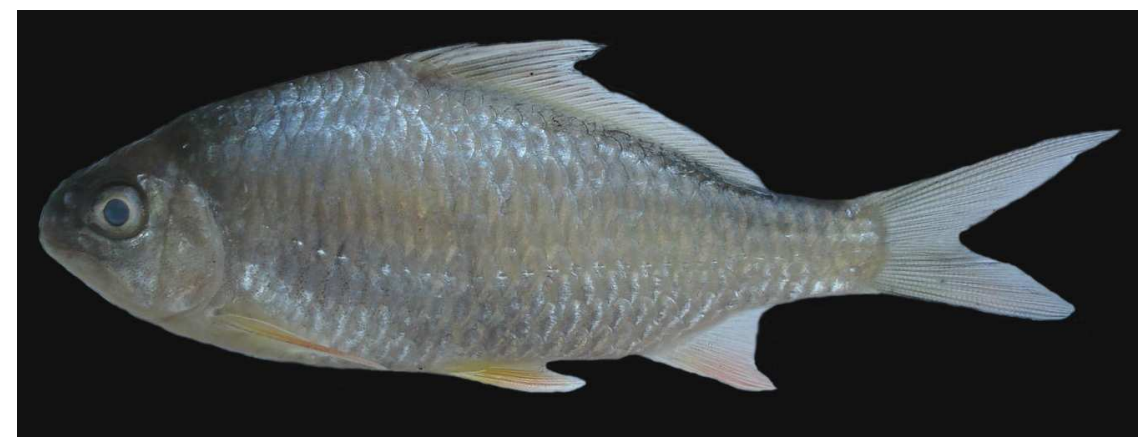

Figure 1. Semiplotus semiplotus McClelland (Male)

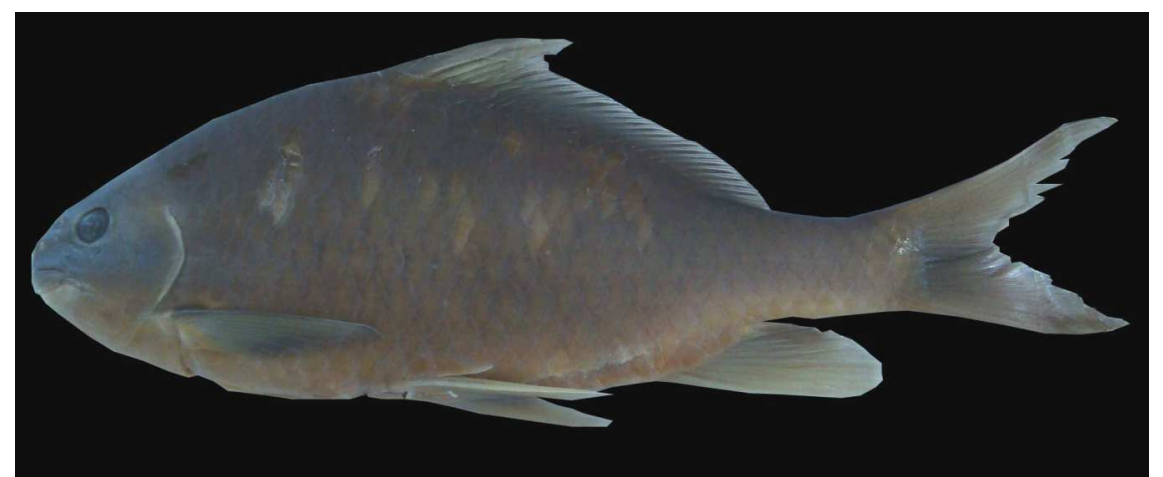

Figure 2. Semiplotus semiplotus McClelland (Female)

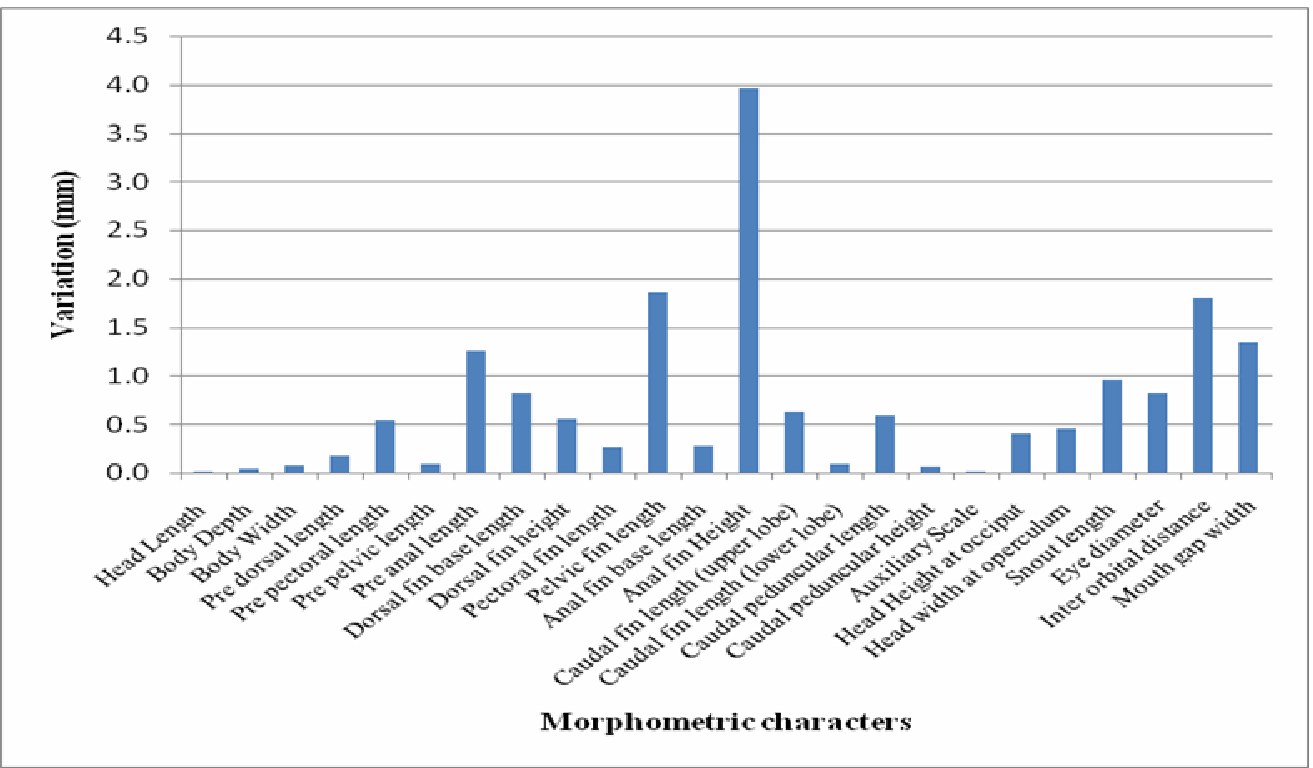

Figure 3. Diffrences in morphometric characters between mature male and female of S. semiplotus. 
K. Bagra, B.A. Laskar and D.N. Das / Our Nature (2009) 7: 158-162

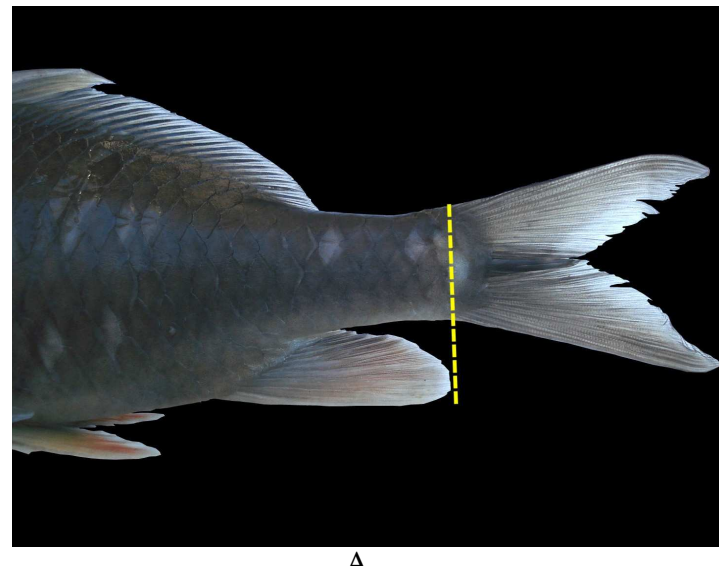

A

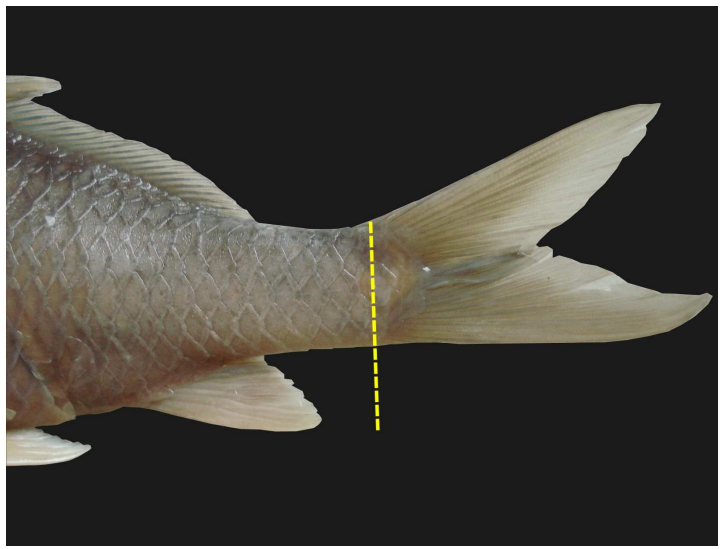

B

Figure 4. Difference in anal fin height of S. semiplotus; (A) Female and (B) Male

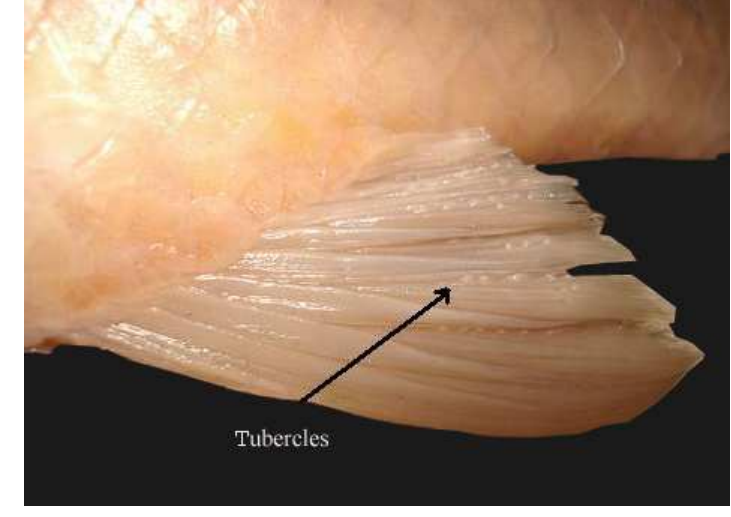

A

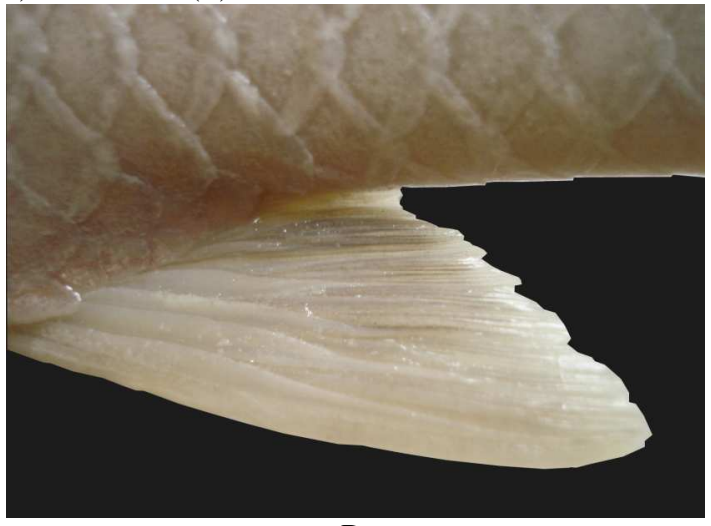

B

Figure 5. Presence of tubercles on anal fin of male; (A) during breeding season and (B) non breeding season.

Table 1. Mean of the comparative morphometric measurements of S. semiplotus in male and female.

\begin{tabular}{|c|c|c|c|c|c|}
\hline \multirow{2}{*}{ In $\%$ of Standard length } & \multicolumn{2}{|c|}{ Male } & \multicolumn{2}{|c|}{ Female } & \multirow{2}{*}{ Variations } \\
\hline & Mean & $\mathrm{SD}$ & Mean & $\mathrm{SD}$ & \\
\hline Head Length & 23.55 & \pm 0.71 & 23.56 & \pm 0.61 & 0.01 \\
\hline Body Depth & 37.53 & \pm 1.51 & 37.56 & \pm 2.34 & 0.03 \\
\hline Body Width & 18.93 & \pm 2.01 & 18.86 & \pm 1.87 & 0.07 \\
\hline Pre dorsal length & 46.04 & \pm 1.66 & 45.87 & \pm 1.60 & 0.17 \\
\hline Pre pectoral length & 23.80 & \pm 1.07 & 23.26 & \pm 0.91 & 0.54 \\
\hline Pre pelvic length & 47.84 & \pm 1.37 & 47.75 & \pm 1.45 & 0.09 \\
\hline Pre anal length & 73.61 & \pm 2.54 & 74.86 & \pm 1.65 & 1.25 \\
\hline Dorsal fin base length & 43.35 & \pm 1.87 & 42.54 & \pm 2.03 & 0.81 \\
\hline Dorsal fin height & 24.26 & \pm 1.99 & 23.71 & \pm 1.12 & 0.55 \\
\hline
\end{tabular}


K. Bagra, B.A. Laskar and D.N. Das / Our Nature (2009) 7: 158-162

\begin{tabular}{|c|c|c|c|c|c|}
\hline Pectoral fin length & 22.91 & \pm 0.86 & 23.17 & \pm 1.00 & 0.26 \\
\hline Pelvic fin length & 25.10 & \pm 5.03 & 23.24 & \pm 1.18 & 1.86 \\
\hline Anal fin base length & 12.72 & \pm 0.67 & 12.45 & \pm 0.51 & 0.27 \\
\hline Anal fin Height & 22.97 & \pm 0.90 & 26.93 & \pm 1.31 & 3.96 \\
\hline Caudal fin length (upper lobe) & 33.66 & \pm 3.39 & 34.29 & \pm 1.60 & 0.63 \\
\hline Caudal fin length (lower lobe) & 31.92 & \pm 2.57 & 32.00 & \pm 1.69 & 0.08 \\
\hline Caudal peduncular length & 16.83 & \pm 2.11 & 16.24 & \pm 2.53 & 0.59 \\
\hline Caudal peduncular height & 11.80 & \pm 0.98 & 11.86 & \pm 0.55 & 0.06 \\
\hline Auxiliary Scale & 10.49 & \pm 0.96 & 10.50 & \pm 0.79 & 0.01 \\
\hline \multicolumn{6}{|l|}{ In $\%$ of Head length } \\
\hline Head Height at occiput & 98.68 & \pm 5.13 & 98.28 & \pm 4.71 & 0.40 \\
\hline Head width at operculum & 77.17 & \pm 3.47 & 76.72 & \pm 2.63 & 0.45 \\
\hline Snout length & 44.16 & \pm 3.48 & 45.11 & \pm 2.48 & 0.95 \\
\hline Eye diameter & 22.28 & \pm 3.37 & 21.46 & \pm 2.56 & 0.82 \\
\hline Inter orbital distance & 53.47 & \pm 3.93 & 55.27 & \pm 3.47 & 1.80 \\
\hline Mouth gap width & 64.92 & \pm 3.36 & 66.26 & \pm 1.83 & 1.34 \\
\hline
\end{tabular}

phenomenon is paradoxical in different species. Identification of the sex in fish through morphometric observation is very important tool to be used in fishery growth and management, like monosex culture and artificial spawning.

\section{Acknowledgements}

The authors are thankful to University Grants Commission, New Delhi, India for financial support in favour of the corresponding author under the scheme of "Research Fellowship in Science for Meritorious Students". Also our sincere regards goes to Rajiv Gandhi University, Rono Hills, Itanagar for providing congenial facilities for this research work.

\section{References}

Conway, K.W. and R. Britz 2007. Sexual dimorphism of the Weberian apparatus and pectoral girdle in Sundadanio axelrodi (Ostariophysi: Cyprinidae). J. Fish Biol. 71: 1562-1570.

Jyoti, M.K. and A. Sharma 2006. Fishes, aid to collection preservation and identification. Daya Publishing House, Delhi. 179p.

Kottelat, M. 2001. Fishes of Laos. Wild life Heritage Trust, Cambodia. 198p.

Nikolsky, G.V. 1963. The ecology of fishes. Academic Press. London and New York.

Park, I.S., C.I. Zhang and Y.D. Lee 2001. Sexual dimorphism in morphometric characters of cocktail wrasse. J. Fish Biol. 58: 1746-1749.

Vishwanath, W. and L. Kosygin 2000. Fishes of the cyprinid genus Semiplotus Bleeker 1859, with description of a new species from Manipur, India. J. Bomb. Nat. Hist. Soc. 97(1): 92-102. 